\title{
Effects of haemodialysis on diabetic macular leakage
}

\author{
Takanobu Tokuyama, Tomohiro Ikeda, Keiko Sato
}

\begin{abstract}
Aim-To evaluate the effects of haemodialysis on macular oedema by fluorescein angiography in patients with diabetic retinopathy and end stage renal disease.

Methods-In this prospective study, fluorescein angiography was performed on 40 eyes of 22 non-insulin dependent diabetic patients with end stage renal disease just before (baseline) and 4 weeks after the beginning of haemodialysis. The change of macular leakage was determined by evaluating the same phase of the angiograms.
\end{abstract}

Results-Fluorescein angiograms obtained at 4 weeks showed that macular leakage was unchanged in $28 / 40$ eyes $(70 \%)$, decreased in $4 / 40$ eyes $(10 \%)$, and increased in $8 / 40$ eyes $(20 \%)$ when compared with the baseline appearance.

Conclusions-These results indicate that haemodialysis does not benefit macular leakage in diabetic patients receiving haemodialysis for end stage renal disease. (Br f Ophthalmol 2000;84:1397-1400)

Macular photocoagulation is commonly used to treat diabetic macular oedema. ${ }^{1-4}$ Recently, vitrectomy has also been reported to be effective in some patients with diabetic macular oedema. ${ }^{5-7}$ In some patients, however, a systemic mechanism is involved in the development of macular oedema ${ }^{8-10}$ and, therefore, the improvement of their systemic conditions is more important. In diabetic patients with end stage renal disease for which haemodialysis therapy will be introduced, fluid retention, hypertension, anaemia, and other abnormal changes in haemodynamic factors may develop that might aggravate macular oedema. Some of

Department of Ophthalmology, Inoue Hospital, Osaka, Japan $\mathrm{T}$ Tokuyama

K Sato

Department of Ophthalmology, Hyogo College of Medicine, Hyogo, Japan T Ikeda

Correspondence to: Dr Tomohiro Ikeda, Department of Ophthalmology, Hyogo College of Medicine, 1-1 Mukogawa-cho,

Nishinomiya-shi, Hyogo 663-8501 Japan tikeda@a2.mbn.or.jp

Accepted for publication 18 May 2000

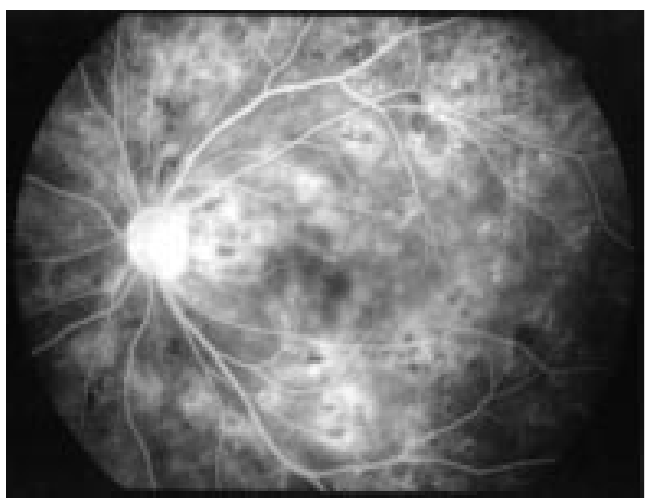
leakage to be unchanged. oedema may be put under close observation in the expectation that the improvement of the haemodynamic factors due to haemodialysis therapy may ameliorate their macular oedema without other therapy, such as photocoagulation or vitrectomy. However, the effect of haemodialysis on diabetic macular oedema has not been closely followed except for a few case reports. ${ }^{11} 12$

The present prospective study used fluorescein angiography to determine whether haemodialysis itself had any effects on macular oedema in patients with diabetic retinopathy and end stage renal disease. We shall show that haemodialysis, in fact, does not alter the macular leakage, and we should thus consider these results in our treatment of patients with diabetic macular oedema.

\section{Patients and methods}

A total of 22 Japanese patients with non-insulin dependent diabetes and end stage renal disease (mean age 58.9 years, range $47-70$ years) were enrolled in this study. Informed consent was obtained from each subject after an explanation of the purpose and potential adverse effects of the procedures.

The patients were diagnosed with either preproliferative or proliferative diabetic retinopathy. Excluded from the study were those with background diabetic retinopathy. None of the patients underwent vitrectomy before the study. Fluorescein angiography (FA) was performed on all patients just before (baseline) and 4 weeks after the beginning of haemodialysis to treat their end stage renal disease.

The patients were placed in three groups depending on the degree of macular leakage observed at the same phase of the fluorescein angiograms - the "unchanged" group that showed no change in macular leakage; the

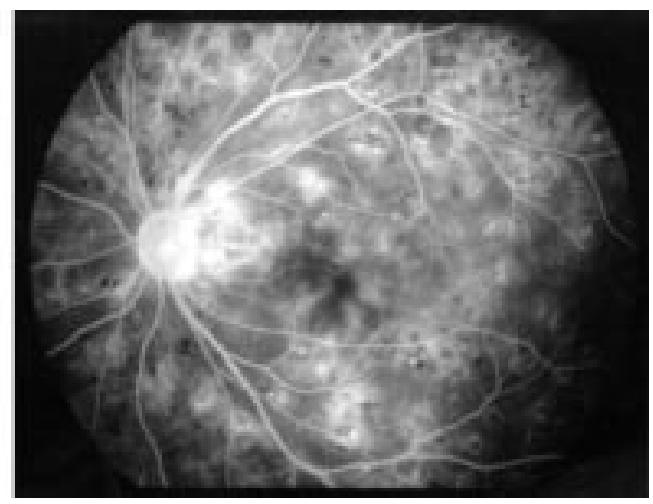

Figure 1 Representative fluorescein angiograms (FAs) of patient 1 from the "unchanged" group (see Table 1). (Left) FA at baseline which shows macular leakage. (Right) FA made 4 weeks after the beginning of haemodialysis shows macular 

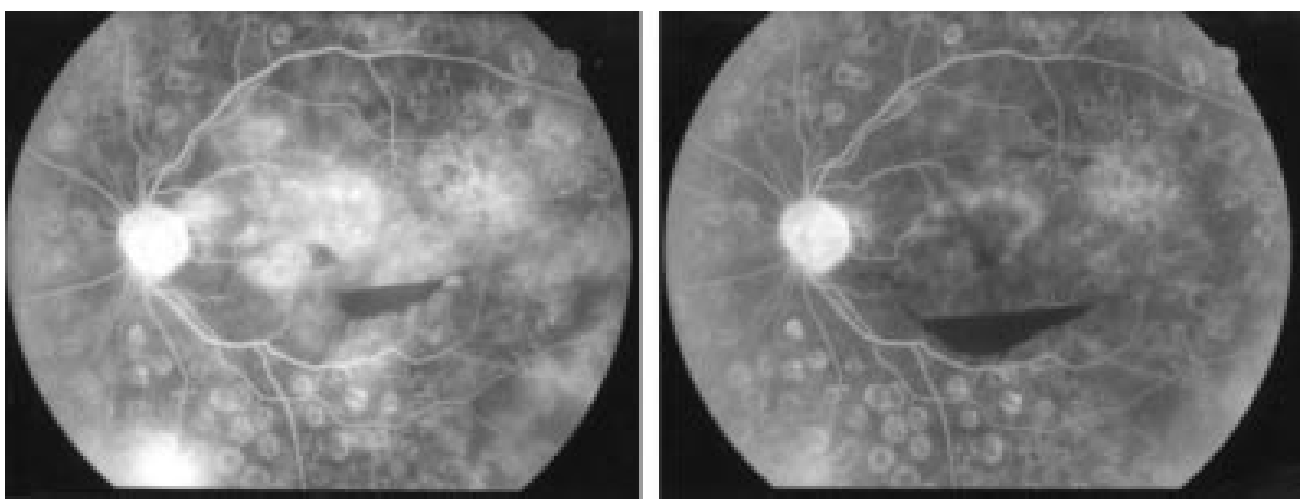

Figure 2 Representative FAs of patient 18 from the "decreased" group (see Table 1). (Left) FA at baseline shows cystoid macular oedema. (Right) FA made 4 weeks after the beginning of haemodialysis shows that the cystoid macular oedema was resolved.
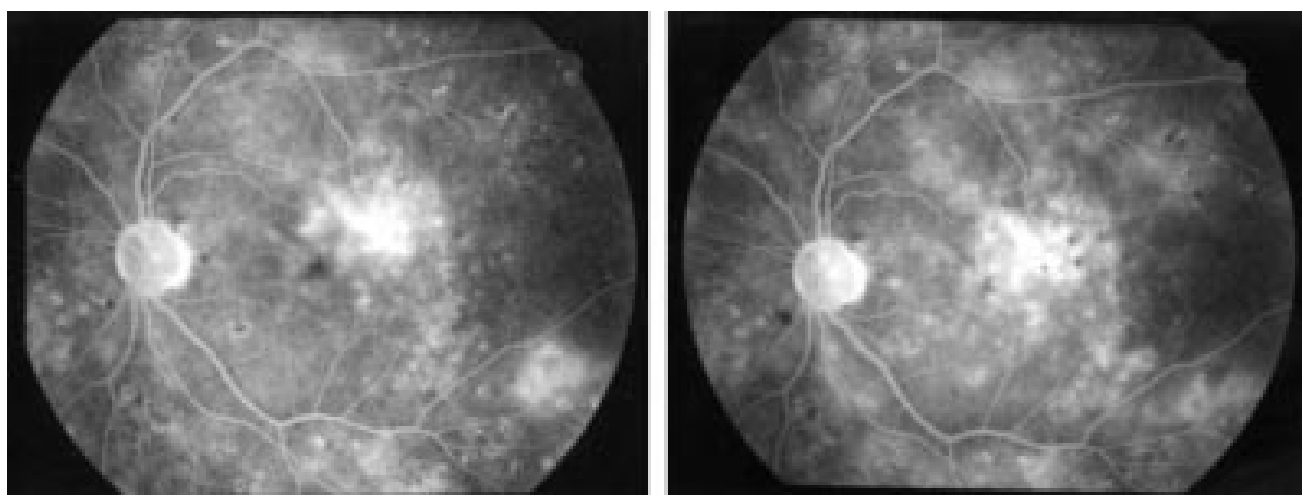

Figure 3 Representative FAs of patient 20 from the "increased" group (see Table 1). (Left) FA at baseline shows macular leakage. (Right) FA made 4 weeks after the beginning of haemodialysis shows cystoid macular oedema.

"decreased" group that showed a decrease in leakage; and the "increased" group that showed an increase in leakage. Grading was done by three independent ophthalmologists who were masked to the purpose of the study. They evaluated the FAs independently, and the grade was recorded only if two or more of the evaluators made the same grade. Representative FAs of each group are shown in Figures $1-3$.

In addition, systemic factors such as blood urea nitrogen (BUN), serum total protein (TP), haematocrit (Ht), body weight, and blood pressure were evaluated in the three groups. Blood was sampled for biochemical and haematological evaluation at baseline before the start of haemodialysis, and again 4 weeks later. Body weight and blood pressure were measured before the start of each haemodialysis session for a period of 4 weeks. The body weight was examined as a relative change - that is, ((the body weight at 4 weeks the body weight at baseline)/the body weight at baseline) $\times 100$. The blood pressure is given as the arithmetic mean of all the measurements for 4 weeks.

Data are presented as means (SD). Statistical analysis was done using a one way and two factor repeated measures ANOVA where appropriate. A level of $\mathrm{p}<0.05$ was accepted as statistically significant.

\section{Results}

Clear fluorescein angiographic images could not be obtained from four eyes because of media opacity caused by vitreous haemorrhage or cataract. We therefore assessed the changes in macular leakage in 40 eyes of the 22 patients. Baseline FAs revealed macular leakage in all 40 eyes. None of the patients had neovascularisation on the optic disc or areas adjacent to the macula that would make it difficult to evaluate any change in macular leakage.

A study of the FAs made 4 weeks after the initiation of haemodialysis showed that the macular leakage was unchanged in 28/40 eyes (70\%) ("unchanged" group), decreased in $4 / 40$ eyes (10\%) ("decreased" group), and increased in $8 / 40$ eyes (20\%) ("increased" group). In 37 of the 40 eyes (92.5\%), the results of grading were consistent among the three evaluators. Of the remaining three eyes, one eye was evaluated as "unchanged" by two evaluators and "decreased" by the third evaluator, and two eyes were evaluated as "decreased" by two and "unchanged" by the remaining evaluator. According to our preset criterion, the former eye was graded as "unchanged" and the latter two eyes were graded as "decreased". In no case did the three evaluators give three different grades.

The systemic profiles of all of the patients are shown in Table 1 , and for each group in Table 2. Biochemical and haematological data-for example, BUN, TP, and Ht, were not significantly different between the three groups $(\mathrm{p}=0.8046, \mathrm{p}=0.0554, \mathrm{p}=0.2803)$. The relative body weight was not significantly different between the groups $(p=0.8868)$. The systolic 
Table 1 Systemic profile of all the patients

\begin{tabular}{|c|c|c|c|c|c|c|c|c|c|c|}
\hline \multirow[b]{2}{*}{ Patient No } & \multirow{2}{*}{$\begin{array}{l}\text { Change of macular } \\
\text { leakage }\end{array}$} & \multicolumn{2}{|c|}{$\begin{array}{l}\text { Blood urea nitrogen } \\
\text { (mg/dl) }\end{array}$} & \multicolumn{2}{|c|}{$\begin{array}{l}\text { Serum total protein } \\
(\mathrm{g} / \mathrm{dl})\end{array}$} & \multicolumn{2}{|c|}{ Haematocrit (\%) } & \multirow{2}{*}{$\begin{array}{l}\text { Changing rate } \\
\text { of body weight } \\
(\%)\end{array}$} & \multirow{2}{*}{$\begin{array}{l}\text { Systolic blood } \\
\text { pressure } \neq(\mathrm{mm} \\
\mathrm{Hg} \text { ) }\end{array}$} & \multirow{2}{*}{$\begin{array}{l}\text { Diastolic blood } \\
\text { pressure } \neq(\mathrm{mm} \\
\mathrm{Hg} \text { ) }\end{array}$} \\
\hline & & Baseline & After & Baseline & After & Baseline & After & & & \\
\hline 1 & BE unchanged & 60 & 63 & 7.1 & 7.5 & 29.6 & 29.5 & -2.6 & 156.5 & 78.2 \\
\hline 2 & BE unchanged & 85 & 78 & 6.1 & 6.1 & 22.2 & 32.0 & -5.5 & 155.5 & 84.4 \\
\hline 3 & $\mathrm{BE}$ unchanged & 135 & 75 & 7.3 & 6.7 & 21.6 & 22.9 & 1.4 & 149.3 & 74.4 \\
\hline 4 & $\mathrm{BE}$ unchanged & 99 & 46 & 6.2 & 6.3 & 21.7 & 32.3 & -3.1 & 172.3 & 83.8 \\
\hline 5 & $\mathrm{BE}$ unchanged & 100 & 93 & 6.1 & 6.7 & 25.0 & 29.7 & -0.4 & 175.5 & 87.8 \\
\hline 6 & BE unchanged & 134 & 81 & 6.9 & 6.7 & 19.7 & 29.9 & 0.8 & 155.0 & 72.3 \\
\hline 7 & $\mathrm{BE}$ unchanged & 77 & 75 & 6.3 & 6.2 & 18.1 & 26.1 & 1.6 & 159.5 & 73.3 \\
\hline 8 & BE unchanged & 95 & 76 & 6.7 & 6.7 & 29.0 & 28.4 & 0.0 & 159.0 & 76.5 \\
\hline 9 & $\mathrm{BE}$ unchanged & 92 & 80 & 7.4 & 7.8 & 27.9 & 27.5 & -1.2 & 163.7 & 82.8 \\
\hline 10 & BE unchanged & 91 & 50 & 6.3 & 6.1 & 26.4 & 27.3 & -0.9 & 145.6 & 80.6 \\
\hline 11 & $\mathrm{BE}$ unchanged & 90 & 68 & 6.6 & 6.5 & 23.8 & 32.0 & -1.1 & 162.7 & 82.3 \\
\hline 12 & LE unchanged & 76 & 75 & 6.7 & 6.8 & 22.6 & 25.3 & -0.9 & 158.1 & 80.8 \\
\hline 13 & LE unchanged & 84 & 59 & 6.6 & 6.5 & 28.7 & 25.6 & -3.4 & 180.0 & 80.4 \\
\hline 14 & RE unchanged & 86 & 69 & 6.1 & 6.0 & 28.8 & 22.9 & -8.7 & 144.5 & 79.5 \\
\hline 15 & RE unchanged & 110 & 66 & 5.5 & 5.4 & 18.4 & 23.0 & -10.9 & 160.2 & 75.9 \\
\hline 16 & $\begin{array}{l}\text { RE decreased } \\
\text { LE unchanged }\end{array}$ & 81 & 73 & 5.9 & 6.0 & 20.8 & 26.9 & -7.4 & 168.4 & 85.1 \\
\hline 17 & $\begin{array}{l}\text { RE unchanged } \\
\text { LE decreased }\end{array}$ & 88 & 58 & 5.9 & 5.4 & 21.1 & 18.1 & 10.3 & 140.4 & 78.3 \\
\hline 18 & $\mathrm{BE}$ decreased & 95 & 65 & 6.7 & 7.1 & 21.0 & 28.2 & 3.9 & 161.9 & 80.6 \\
\hline 19 & $\mathrm{BE}$ increased & 79 & 60 & 7.0 & 6.2 & 25.7 & 23.9 & 1.4 & 161.0 & 75.6 \\
\hline 20 & $\mathrm{BE}$ increased & 106 & 83 & 6.9 & 6.6 & 34.0 & 29.5 & -0.3 & 171.8 & 98.6 \\
\hline 21 & $\mathrm{BE}$ increased & 134 & 83 & 7.0 & 7.0 & 24.8 & 26.9 & 1.5 & 171.0 & 84.7 \\
\hline 22 & $\mathrm{BE}$ increased & 61 & 38 & 4.2 & 4.1 & 20.6 & 27.9 & -12.2 & 161.0 & 75.6 \\
\hline
\end{tabular}

${ }^{\star} \mathrm{BE}=$ both eyes; $\mathrm{RE}=$ right eye, $\mathrm{LE}=$ left eye. The fellow eye in four patients (patients 12-15) could not be assessed for change in macular leakage because of media opacity.

t(The body weight at 4 weeks after the initiation of $\mathrm{HD}-$ the body weight at baseline)/the body weight at baseline $) \times 100$.

$\ddagger$ The blood pressure is given as the arithmetic mean of all the measurements for 4 weeks.

Table 2 Systemic profile of each group

\begin{tabular}{|c|c|c|c|c|c|c|c|c|c|c|}
\hline \multirow[b]{2}{*}{ Group } & \multirow{2}{*}{$\begin{array}{l}\text { Total no } \\
\text { of eyes }\end{array}$} & \multicolumn{2}{|c|}{ Blood urea nitrogen $(\mathrm{mg} / \mathrm{dl})$} & \multicolumn{2}{|c|}{ Serum total protein $(g / d l)$} & \multicolumn{2}{|c|}{ Haematocrit (\%) } & \multirow{2}{*}{$\begin{array}{l}\text { Changing rate of } \\
\text { body weight } \\
(\%)\end{array}$} & \multirow{2}{*}{$\begin{array}{l}\text { Systolic blood } \\
\text { pressuret } \\
\text { (mmHg) }\end{array}$} & \multirow{2}{*}{$\begin{array}{l}\text { Diastolic blood } \\
\text { pressuret } \\
\text { (mmHg) }\end{array}$} \\
\hline & & Baseline & After & Baseline & After & Baseline & After & & & \\
\hline Unchanged & 28 & $94(20)$ & $70(12)$ & $6.5(0.5)$ & $6.5(0.6)$ & $24.0(3.8)$ & $27.8(3.6)$ & $-1.5(4.0)$ & $160(9)$ & $80(5)$ \\
\hline Decreased & 4 & $90(7)$ & $65(6)$ & $6.3(0.5)$ & $6.4(0.8)$ & $21.0(0.1)$ & $25.4(4.9)$ & $-1.2(7.9)$ & $159(10)$ & $81(3)$ \\
\hline Increased & 8 & $95(30)$ & $66(20)$ & $6.3(1.3)$ & $6.0(1.2)$ & $26.3(5.2)$ & $27.1(2.2)$ & $-2.4(6.1)$ & $166(6)$ & $84(10)$ \\
\hline
\end{tabular}

*(The body weight at 4 weeks after the initiation of $\mathrm{HD}-$ the body weight at baseline)/the body weight at baseline $) \times 100$.

†The blood pressure is given as the arithmetic mean of all the measurements for 4 weeks.

and diastolic blood pressures were also not significantly different in the three groups $(\mathrm{p}=0.1976, \mathrm{p}=0.2713)$.

\section{Discussion}

The low serum protein often accompanying renal failure should reduce the plasma colloidal osmotic pressure, and the hypertension should increase the hydrostatic pressure in the retinal capillaries. Systemic cardiovascular diseases can increase the blood volume. These haemodynamic factors should increase the retinal vascular leakage in diabetic patients who already have a malfunction of the retinal capillary endothelium ${ }^{13}$ and an impairment of the autoregulation of retinal blood flow. ${ }^{14-16}$ Bresnick $^{11}$ believed that the treatment of these haemodynamic disorders should alleviate diabetic macula oedema. He reported a decrease in diabetic macular leakage in a 31 year old woman 1 month after the initiation of peritoneal dialysis. Perkovich and Meyers ${ }^{12}$ reported a patient whose diabetic macular oedema was resolved with a decrease in macular leakage 1 month after the beginning of haemodialysis. The retinal changes were accompanied by an improvement in systemic hypertension and fluid retention. The present prospective study assessed the effects of haemodialysis on macular oedema by comparing the macular leakage just before and 4 weeks after the initiation of haemodialysis.
Haemodialysis is administered to patients with end stage renal disease to treat their oedema and uraemia. Both the volume and the composition of body fluid changed markedly after haemodialysis. A disordered inner bloodretinal barrier and an impaired autoregulation of retinal blood flow have been demonstrated in diabetic patients. While an impaired autoregulation of retinal blood flow was not proved in the present study because of methodological difficulties, pre-dialysis FAs revealed macular leakage in all 40 eyes that indicated that the inner blood-retinal barrier was damaged to some extent.

The change in body fluid volume that parallels the change in plasma volume may affect macular leakage in haemodialysis patients with diabetic retinopathy. In the present study, however, macular leakage was unchanged in 28 of 40 eyes $(70 \%)$ at 4 weeks after the initiation of haemodialysis. This indicated that haemodialysis has little effect on macular leakage in diabetic retinopathy despite the clinical expectations.

To explain this unexpected observation, one might speculate that the inner blood-retinal barrier and the autoregulation of retinal blood flow were sufficiently preserved to protect the capillaries from the dynamic changes in blood volume that occur after haemodialysis.

Another possible explanation for the lack of change on macular leakage is the mechanisms 
that are thought to exist for maintaining the balance between plasma volume and the dynamic change in fluid volume in patients receiving haemodialysis. Bauer and Brooks ${ }^{17}$ assessed the alterations in body fluid composition in haemodialysis patients after the infusion of isotonic saline to increase body weight by approximately $2 \mathrm{~kg}$ and after haemodialysis that decreased body weight by approximately 2 $\mathrm{kg}$. Although the extracellular fluid volume, which consists of the plasma volume and interstitial fluid volume, increased after saline infusion and decreased after dialysis, the plasma volume did not differ before and after dialysis. They concluded that the change in extracellular fluid volume involved only a change in interstitial fluid volume that acts as a buffer zone to maintain a balance between plasma volume and the dynamic change in fluid volume in patients receiving haemodialysis. Fauchald ${ }^{18}$ demonstrated that colloid osmotic pressure, which is dependent on the concentration of proteins, ${ }^{19}$ tends to preserve the plasma volume despite the dynamic change in fluid volume that occurs during haemodialysis. In brief, the predialysis fluid retention leads to an increase in plasma volume that involves a decrease in plasma colloid osmotic pressure. Because this decrease produces a colloid osmotic gradient between the plasma and the interstitial fluid, water is pushed from the plasma into the interstitial fluid. In contrast, following haemodialysis, the removal of water from the plasma leads to an increase in plasma colloid osmotic pressure and causes water to shift from the interstitial fluid into the plasma. Thus, the balance between plasma volume and the dynamic change in fluid volume in patients receiving haemodialysis is thought to be maintained. In the presence of these mechanisms, haemodialysis would have little influence on the retinal circulation, even with disorders of the inner blood-retinal barrier and autoregulation of retinal blood flow.

Although most of the patients studied did not demonstrate a change in macular leakage 4 weeks after the beginning of haemodialysis, some of the patients did. In order to study whether the changes in these patients were dependent on the degree of predialysis oedema, a subgroup of patients who showed cystoid macular oedema before haemodialysis was analysed for any haemodialysis related changes in macular leakage. In this subgroup, macular leakage was "decreased" in two eyes, including the eye shown in Figure 2, "unchanged" in four eyes, and "increased" in only one eye shown in Figure 3. Considering the difficulty in evaluating the degree of macular oedema, we selected for analysis these patients showing severe macular oedema and found that the degree of predialysis oedema was independent of haemodialysis related changes in macular leakage.

An examination of the systemic profile of our patients did not reveal any relevant findings. We had expected that hypertension, in particular, might be involved in the increase in macu- lar leakage, because fluid retention is a major cause of hypertension in patients with end stage renal disease. ${ }^{20}$ However, we found no obvious relation between blood pressure and an increase in macular leakage.

One patient with severe hypoproteinaemia (patient 22, Table 1) showed an increase in macular leakage. Hypoproteinaemia, which would increase the shift of water from the plasma into the interstitial fluid, might impair the balance between the plasma volume and dynamic change in fluid volume during haemodialysis. We suggest that hypoproteinaemia might be a cause of an increase in macular leakage during haemodialysis.

Our results indicated that haemodialysis did not improve the macular leakage in most patients. We thus recommend that patients with diabetic macular oedema undergoing haemodialysis should receive the appropriate ophthalmological treatment for this disease without the expectation that haemodialysis might alleviate macular leakage.

1 British Multicentre Study Group. Photocoagulation in reatment of diabetic maculopathy. Lancet 1975;2:111013.

2 British Multicentre Study Group. Photocoagulation for diabetic maculopathy. Diabetes 1983;32:1010-6.

3 Early Treatment Diabetic Retinopathy Study Research Group. Photocoagulation for diabetic macular edema: number 1. Arch Ophthalmol 1985;103:1796-806.

4 Early Treatment Diabetic Retinopathy Study Research Group. Photocoagulation for diabetic macular edema: Early Treatment Diabetic Retinopathy Study report Early Treatment Diabetic Retinopathy Study

5 Lewis H, Abrams GW, Blumenkranz MS, et al. Vitrectomy for diabetic macular traction and edema associated with posterior hyaloidal traction. Ophthalmology 1992;99:753-9.

6 Harbour JW, Smiddy WE, Flynn HW Jr, et al. Vitrectomy for diabetic macular edema associated with a thickened and taut posterior hyaloid membrane. Am $f$ Ophthalmol 1996;121:405-13

7 Ikeda T, Sato K, Katano T, et al. Vitrectomy for cystoid macular oedema with attached posterior hyaloid mem$12-14$.

8 Berman DH, Friedman EA. Partial absorption of hard exudates in patients with diabetic end-stage renal disease and severe anemia after treatment with erythropoietin. Retina 1994;14:1-5.

9 Freidman EA, Brown CD, Berman DH. Erythropoietin in diabetic macular edema and renal insufficiency. Am f Kidney Dis 1995;26:202-8.

10 Klein R, Klein BE, Moss SE, et al. The Wiscosin Epidemiologic Study of Diabetic Retinopathy:XVII. The 14-year incidence and progression of diabetic retinopathy and associated risk factors in type 1 diabetes. Ophthalmology 1998;105:1801-15.

11 Bresnick GH. Diabetic maculopathy. A critical review highlighting diffuse macular edema. Ophthalmology 1983;90: 1301-17.

12 Perkovich BT, Meyers SM. Systemic factors affecting diabetic macular edema. Am f Ophthalmol 1988;105:211-

13 Cunha-Vaz JG, Fonseca JR, Abreu JR, et al. Detection of early retinal changes in diabetes by vitreous fluorophotometry. Diabetes 1979;28:16-9.

14 Fallon TJ, Maxwell DL, Kohner EM. Autoregulation of retinal blood flow in diabetic retinopathy measured by the retinal blood flow in diabetic retinopathy measured by the
blue-light entoptic technique. Ophthalmology 1987;94: blue-light

15 Kohner EM. The retinal blood flow in diabetes. Diabetes Metab 1993;19:401-4.

16 Rassam SM, Patel V, Kohner EM. The effect of experimental hypertension on retinal vascular autoregulation in humans: a mechanism for the progression of diabetic retinopathy. Exp Physiol 1995;80:53-68.

17 Bauer JH, Brooks CS. Body fluid composition in chronic renal failure. Clin Nephrol 1981;16:114-8.

18 Fauchald P. Transcapillary colloid osmotic gradient and body fluid volumes in renal failure. Kidney Int 1986;29: 895-900.

19 Milnor WR. Capillaries and lymphatic vessels. In: Mountcastle VB, ed. Medical physiology. 12th ed. St Louis: CV Mosby, 1968:134-49.

20 Vertes V, Cangiano JL, Berman LB, et al. Hypertension in end-stage renal disease. $N$ Engl f Med 1969;280:978-81 